\title{
KINETICS OF 1-PENTANOL ETHERIFICATION WITHOUT WATER
}

\section{REMOVAL}

Roger Bringué*, Eliana Ramírez, Carles Fité, Montserrat Iborra and Javier Tejero

Dept. of Chemical Engineering, University of Barcelona. C/ Martí i Franquès, 1, 08028Barcelona, SPAIN *Corresponding author: Phone: +34 93 4020155; Fax: +34 93 4021291;

E-mail: rogerbringue@ub.edu

\section{Abstract}

The effect of water on the kinetics of the liquid-phase dehydration of 1-pentanol to di- $n$ pentyl ether (DNPE) and water over Amberlyst 70 is revisited. To explain the strong inhibitor effect of water, two approaches were compared. Firstly, a model stemming from a Langmuir- Hinshelwood-Hougen-Watson (LHHW) mechanism was used, wherein the inhibitor effect of water was explained by the competitive adsorption of water and pentanol. Secondly, a modified Eley-Rideal (ER) model that includes an inhibition factor, in which a Freundlich-like function is used to explain the inhibitor effect of water by blocking the access of pentanol to the active centers. Both models fitted data quite well, although the best results were obtained with the modified ER model. The activation energy was $118.7 \pm$ $0.2 \mathrm{~kJ} / \mathrm{mol}$ for the LHHW model and $114.0 \pm 0.1 \mathrm{~kJ} / \mathrm{mol}$ for the modified ER one.

Keywords: inhibiting effect of water, 1-pentanol, DNPE, Amberlyst 70, Reaction kinetics

\section{Introduction}

Adsorption of chemicals on the solid surface is the key step of solid catalyzed reactions, so that interaction among one or more of the different species present in the medium with 
catalyst surface is essential for the reaction to proceed. Frequently, some reactant or reaction product adsorbs preferably determining in this way the catalyst activity, i.e. polar species onto sulfonic styrene/divinylbenzene (S/DVB) resins. In such catalysts acidity and accessibility of sulfonic groups to catalyze the reaction change over reaction medium composition because of polymer swelling by the preferential adsorption of species such as water or alcohol what decreases, as a result, the reaction rate ${ }^{1}$.

This rate-inhibiting effect of polar species on S/DVB resins is advantageously used to maximize the yield of the intermediate product in series reactions by limiting the yield of final products, e.g. alcohols $s^{2,3}$ and water ${ }^{4,5}$ are reported as selectivity enhancers in olefin oligomerization, favoring dimers formation and hindering that of trimers and higher oligomers. More often, this effect is undesirable when such polar species, in particular water, are reaction products. As a highly polar species, it preferably adsorbs on sulfonic S/DVB resins with a rate-inhibiting effect both in gas phase ${ }^{6}$ and in liquid phase reactions ${ }^{7-}$ ${ }^{19}$. Kinetics of liquid-phase reactions with water formation (alcohol dehydration to olefins, bisphenol A synthesis, etc) is complex since the very first amount of water produced inhibits the reaction, whereas further water released acts as a solvent ${ }^{7}$, what swells the resin and increases accessibility to inner active centers. This process is accompanied simultaneously by a transition from general to specific acid catalysis, generally slower ${ }^{7}$. The rate-inhibiting effect of water is also ascribed to its great affinity for sulfonic groups, so that it excludes the reactants and suppresses the catalytic reaction almost completely ${ }^{20,21}$. However, it is to be noted that, despite its rate-inhibiting effect, water is reported to improve the catalyst's lifetime ${ }^{16}$.

7 Langmuir-Hinshelwood-Hougen-Watson (LHHW) or its related Eley-Rideal (ER) kinetic models are widely used to represent rate data of liquid-phase reactions of alcohol 
dehydration to ether ${ }^{10,22-24}$, but some inaccuracies appear because of the reaction mediumcatalyst interaction, specially on catalysts with a flexible backbone as S/DVB resins. To quantify the effect of such interaction, empirical corrections are suggested in the open literature. Water effect has been represented by using empirical exponents in the driving force and the adsorption term of LHHW or ER rate-expressions, i.e. for tert-butanol dehydration $^{7}$, esterification of acetic acid with amyl alcohol ${ }^{12}$ or synthesis of tertiary amyl alcohol $^{25}$. In the particular case of liquid-phase etherification reactions, a second approach is found: water effect on the reaction rate is quantified by splitting off the rate constant, $\hat{k}$, into two factors as a product of the true rate constant, $\hat{k}_{o}$, and an inhibition factor, which should take values between 0 and 1 and depends on temperature and water activity, $a_{w}$, in the liquid-phase. Such factor is analogous to those mostly used to describe catalyst deactivation by poisoning and, at first sight, it can be seen as the fraction of active centers free of water ${ }^{17-19},\left(1-\theta_{w}\right)$, i.e.,

$$
\hat{k}=\hat{k}_{o} \cdot f\left(a_{w}, T\right)=\hat{k}_{o}\left(1-\theta_{w}\right)
$$

In a previous work, the liquid phase dehydration of 1-pentanol to DNPE without water removal was studied on gel and macroporous acidic S/DVB resins, including sulfonated and over-sulfonated ones ${ }^{26,27}$. Gel-type and low-crosslinking macroporous resins were found to be very selective to DNPE and, therefore, they are suitable catalysts for the reaction. Among tested resins, the thermally stable Amberlyst 70, which is able to operate up to $463 \mathrm{~K}$, was proposed for industrial use, since it showed the highest conversion and yield in the temperature range 423-463 K. Its performance in this temperature range was even better than Nafion NR50 or H-Beta zeolite. 
In a first approach to obtain the reaction kinetics, necessary for reactor design purposes,

72 it was found that a kinetic model based on an ER mechanism, in which the rate-limiting step was the surface reaction between adsorbed 1-pentanol and an alcohol molecule from the liquid phase and without a significant number of unoccupied active centers, represented reasonably well rate data for all the tested catalysts ${ }^{27}$ :

$$
r_{D N P E}=\frac{\hat{k} \cdot a_{P}^{2}}{a_{P}+\left(K_{D} / K_{p}\right) \cdot a_{D}}
$$

$K_{D}$ and $K_{P}$ are the adsorption equilibrium constants of DNPE and 1-pentanol; $a_{D}$ and $a_{p}$,

their liquid-phase activities, respectively, and $\hat{k}$ the rate constant. However, at 453 and 463 $\mathrm{K}$ some inaccuracies were noted in the case of Amberlyst 70. As a consequence the rate model should be upgraded, by considering (a) the reverse reaction and (b) the effect of water in the reaction rate, seeing that water activity does not accounts in eq.(2), despite the fact that water adsorbs in large amounts in ion-exchange resins. were determined experimentally ${ }^{28}$. Moreover, the inhibiting effect of water on the rate of the liquid-phase dehydration of 1-pentanol to DNPE was stated experimentally and some kinetic models including water effect were proposed ${ }^{29}$. A complete and exhaustive kinetic study of the reaction including the last findings on the reaction is thus suitable. As a consequence, the aim of this work is to perform a comprehensive kinetic analysis of DNPE synthesis on Amberlyst 70 by including both (a) the effect of the reverse reaction and (b) new rate data obtained in the presence of additional water and ether amounts, in such a way that it was possible to discriminate a good kinetic model able to predict reaction rate in a wide range of alcohol, ether and water concentrations. 


\section{Experimental}

\subsection{Materials}

1-Pentanol (99\% pure, <1\% 2-methyl-1-butanol), supplied by Fluka, and bidistilled water were used without further purification. DNPE ( $\geq 99 \%)$ was produced and purified in our laboratory. Amberlyst 70 (Rohm \& Haas), a macroporous sulfonic styrene-DVB resin stable up to $473 \mathrm{~K}$ (surface area $29.9 \mathrm{~m}^{2} / \mathrm{g}$ when dried by successive percolation with methanol, toluene and isooctane; concentration of acid sites $3 \mathrm{eq} \mathrm{H}^{+} / \mathrm{kg}$ ) was used as the catalyst.

\subsection{Apparatus}

Experiments were carried out in a $100 \mathrm{~mL}$ stainless steel autoclave operated in batch mode. A magnetic drive turbine was used as stirring device and baffles were placed inside the reactor to improve mixing. Temperature was controlled to within $\pm 1 \mathrm{~K}$ by an electric furnace. The pressure was set at $1.6 \mathrm{MPa}$ by means of $\mathrm{N}_{2}$, in order to maintain the liquid phase over the whole temperature range. One of the outlets was connected directly to a liquid sampling valve, which injected $0.2 \mu \mathrm{L}$ of liquid into a GLC chromatograph.

\subsection{Analysis}

The liquid composition was analyzed by a split operation mode in a HP6890A GLC apparatus equipped with a TCD detector. A $50 \mathrm{~m} \times 0.2 \mathrm{~mm} \times 0.5 \mu \mathrm{m}$ methyl silicone capillary column was used to quantify concentration of 1-pentanol, DNPE, water, 1pentene, 2-pentene, and branched ethers 1-(1-methyl-butoxy)-pentane, 1-(2-methylbutoxy)-pentane, 2-(1-methyl-butoxy)-pentane, and 2-(2-methyl-butoxy)-pentane. The temperature of the column was held at $318 \mathrm{~K}$ for $6 \mathrm{~min}$, increased at a rate of $30 \mathrm{~K} / \mathrm{min}$ up 
115 to $453 \mathrm{~K}$, and held for $2 \mathrm{~min}$. Helium was used as carrier gas at a total flow rate of 30 $116 \mathrm{~mL} / \mathrm{min}$.

\section{$117 \quad 2.3$ Procedure}

118 Fresh catalyst and $70 \mathrm{~mL}$ of 1-pentanol (1-pentanol-water or 1-pentanol-DNPE where 119 appropriate) were charged into the reactor and, after checking for leakages, heated to the 120 working temperature. The resin was dried for $1 \mathrm{~h}$ in atmospheric oven at $383 \mathrm{~K}$, and then for

$1212 \mathrm{~h}$ at vacuum $(<0.1 \mathrm{mmHg})$. Zero time was set when the reaction medium reached 122 working temperature. To monitor the concentration variation of chemicals along time, very 123 small liquid samples, which do not disturb the reacting system, were taken out of the 124 reactor and analyzed hourly. Reaction rates of DNPE formation were estimated as indicated 125 elsewhere ${ }^{27}$, being accurate within $\pm 5 \%$. On the other hand, in all the experiments mass 126 balance was fulfilled within $\pm 2 \%$.

\section{Results and discussion}

\subsection{Preliminary experiments}

129 Firstly preliminary runs were conducted at $463 \mathrm{~K}$ to check that measured rates were free

130 of mass transfer effects. All the experiments were performed on $1 \mathrm{~g}$ of catalyst, since

131 previous results with the same set-up showed that with a catalyst mass $\leq 2 \mathrm{~g}$, measured

132 rates were independent on the amount of used catalyst ${ }^{27,30}$.

133 Diffusion rate of chemicals through porous solids depends on temperature and particle

134 size. To measure intrinsic reaction rates experimentally, and so have an accurate kinetic 135 model, it is basic to work within the particle diameter, $d_{p}$, range where such influence is 136 negligible. Internal mass transfer influence can be evaluated by testing catalyst batches of 137 different particle size. Figure 1 (up) plots DNPE mole profile along time for different 
138 particle size batches, whereas in Figure 1 (down) the initial reaction rate at $463 \mathrm{~K}$ is plotted

139 against the reciprocal of resin mean particle diameter. Open circles correspond to 140 Amberlyst 70 sieved fractions of $0.316,0.502,0.710$ and $>0.8 \mathrm{~mm}$, respectively, and the 141 black rhombus refers to the mean diameter of commercial beads $(0.570 \mathrm{~mm})$. As Figure 1

142 (up) shows, internal mass transfer influence is negligible at $463 \mathrm{~K}$ within the limits of the 143 experimental error in the particle size range explored, and therefore also at lower 144 temperatures, although the DNPE mole profile for $d_{p}=0.7 \mathrm{~mm}$ is slightly higher than the 145 others after $6 \mathrm{~h}$. This fact is ascribed to the accumulation of the experimental error 146 throughout the whole experiment, since no deviation was observed on the commercial 147 distribution of particle diameters.

148 External mass transfer influence was evaluated by performing a series of experiments by 149 changing stirring speed, $N$, between 50 and $700 \mathrm{rpm}$, also at $463 \mathrm{~K}$, where such influence 150 could be more notorious. In Figure 2 DNPE mole evolution versus time at different stirring 151 speeds and the initial reaction rate versus stirring speed are shown. As can be seen, initial 152 reaction rates are the same, within the limits of experimental error, for $\mathrm{N} \geq 200 \mathrm{rpm}$, 153 whereas DNPE mole profiles overlap except when $\mathrm{N}=700$ and $50 \mathrm{rpm}$.

154 As a consequence, to measure intrinsic reaction rates of DNPE synthesis henceforth, 155 experiments were performed at $\mathrm{N}=500 \mathrm{rpm}$ on catalyst samples of $1 \mathrm{~g}$ of dry catalyst 156 having the commercial distribution of particle sizes.

\subsection{Experiments starting with pure 1-pentanol}

158 A first series of replicated experiments were done in the temperature range $413-463 \mathrm{~K}$ 159 starting from pure 1-pentanol ${ }^{27}$. Figure 3 shows DNPE production along the runs. As 160 expected, reaction rate is highly dependent on temperature. The slope of $n_{D N P E}$ vs. time, 161 which is related to reaction rate, diminishes along time due to the effect of the reverse 
162 reaction and/or some inhibition effect. In all the runs, selectivity to ether was higher than $16393 \%$.

164 As the reaction mixture is non-ideal, kinetic analysis is given in terms of activities of 1165 pentanol $\left(a_{P}\right)$, DNPE $\left(a_{D}\right)$, and water $\left(a_{W}\right)$. Activity coefficients were computed by the 166 UNIFAC-DORTMUND predictive method $^{31}$. The dependence of the reaction rate as a 167 function of $a_{P}, a_{D}$ and $a_{W}$ is shown in Figure 4. As seen, reaction rate increases on 168 increasing $a_{P}$ in the entire range of explored activities and temperatures, whereas it 169 decreases on increasing $a_{D}$ and $a_{W}$. These facts suggest that a hyperbolic model, based on a

170 LHHW or ER mechanism, could explain satisfactorily rate data. Figure 4 (up) suggests that $171 a_{P}$ influences chiefly the numerator of such a kinetic model, so promoting forward reaction. 172 The rate-decreasing effect showed by $a_{D}$ and $a_{W}$ (Figures 4 (middle and down)) can be 173 attributed to a preferential adsorption onto the resin of the ether and water, and also, as they 174 are reaction products, to the enhancement of the reverse reaction as the system approaches 175 to chemical equilibrium ${ }^{32-33}$. Based on the analysis of the reaction rate dependence, and 176 considering the adsorption-reaction-desorption process, the following reaction mechanisms 177 could be proposed:

178 Mechanism 1: two 1-pentanol molecules adsorbed on an active site, respectively, react 179 to give the ether and water (LHHW type)

$180 \quad 1-\mathrm{PeOH}+\sigma \rightleftharpoons 1-\mathrm{PeOH} \cdot \sigma$

$181 \quad 2(1-\mathrm{PeOH} \cdot \sigma) \rightleftharpoons \mathrm{DNPE} \cdot \sigma+\mathrm{W} \cdot \sigma$

$182 \quad \mathrm{DNPE} \cdot \sigma \rightleftharpoons \mathrm{DNPE}+\sigma$

$183 \quad \mathrm{~W} \cdot \sigma \rightleftharpoons \mathrm{W}+\sigma$ 
184 Mechanism 2: 1-pentanol from solution reacts with 1-pentanol adsorbed on one active 185 centre to give the ether adsorbed on the resin surface, the water being released 186 instantaneously to the liquid phase (ER type)

$187 \quad 1-\mathrm{PeOH}+\sigma \rightleftharpoons 1-\mathrm{PeOH} \cdot \sigma$

$188 \quad 1-\mathrm{PeOH} \cdot \sigma+1-\mathrm{PeOH} \rightleftharpoons \mathrm{DNPE} \cdot \sigma+\mathrm{W}$

$189 \quad \mathrm{DNPE} \cdot \sigma \rightleftharpoons \mathrm{DNPE}+\sigma$

$190 \quad$ Mechanism 3: 1-pentanol from solution reacts with 1-pentanol adsorbed on one active 191 site, the ether being released directly to the liquid phase (ER type),

$192 \quad 1-\mathrm{PeOH}+\sigma \rightleftharpoons 1-\mathrm{PeOH} \cdot \sigma$

$193 \quad 1-\mathrm{PeOH} \cdot \sigma+1-\mathrm{PeOH} \rightleftharpoons \mathrm{W} \cdot \sigma+\mathrm{DNPE}$

$194 \quad \mathrm{~W} \cdot \sigma \rightleftharpoons \mathrm{W}+\sigma$

195 By assuming that surface reaction is the rate-limiting step, the following kinetic models 196 were obtained for mechanisms 1,2 and 3, respectively:

197

$$
r_{D N P E}=\frac{\hat{k} \cdot K_{P}^{2}\left(a_{P}^{2}-\frac{a_{W} a_{D}}{K}\right)}{\left(1+K_{P} a_{P}+K_{D} a_{D}+K_{W} a_{W}\right)^{2}}
$$

198

$$
r_{D N P E}=\frac{\hat{k} \cdot K_{P}\left(a_{P}^{2}-\frac{a_{W} a_{D}}{K}\right)}{1+K_{P} a_{P}+K_{D} a_{D}}
$$

$$
r_{D N P E}=\frac{\hat{k} \cdot K_{P}\left(a_{P}^{2}-\frac{a_{W} a_{D}}{K}\right)}{1+K_{P} a_{P}+K_{W} a_{W}}
$$

200 On the basis of these equations, all possible kinetic models derived by considering one 201 or more factors of adsorption term being negligible were fitted to rate data. A detailed schedule of models handled can be found elsewhere ${ }^{34,35}$. For fitting purposes, all the models 
were grouped into two classes, depending on the number of free active centers (see Table 1):

(i) Class I, for which the number of free active centers is considered to be negligible compared to occupied ones. This fact implies that the unity present in the adsorption term is removed.

(ii) Class II, where that hypothesis is rejected.

209 For models of Class I, the surface rate constant, $\hat{k}$, and the adsorption equilibrium 210 constants, $K_{P}, K_{D}$, and $K_{W}$, have been grouped into factors, called $\mathrm{A}, \mathrm{B}$, and $\mathrm{C}$, for 211 mathematical fitting purposes. The particular form how constants are grouped depends on 212 the mechanism (LHHW or ER) and the neglected adsorption term, if any. Concerning the 213 models of class II, $k_{1}$ is equal to $\hat{k} K_{P}^{2}$ for LHHW models and to $\hat{k} K_{P}$ for ER models. The 214 temperature dependence of such factors was defined as follows:

$$
A, B, C, k_{1}=\exp \left(b_{i}\right) \exp \left[-b_{i+1}\left(\frac{1}{T}-\frac{1}{\bar{T}}\right)\right]
$$

216 where $\bar{T}$ is the mean experimental temperature. To take into account the influence of the 217 reverse reaction, the temperature dependence of the thermodynamic equilibrium constant, $218 K$, was computed as ${ }^{28}$

$$
K=\exp \left(\frac{783.42}{T}+2.18\right)
$$

Fitted parameters of the models shown in Table 1 were $b$ 's, as appeared in Equation 6.

221 The subtraction of the inverse of the mean experimental temperature was included to minimize the correlation among fitted parameters $b_{i}$ and $b_{i+1}$.

223 From a mathematical point of view, the most suitable model is the one in which the minimum sum of squared residuals $(S S R)$, residuals randomness, and lower parameter 
correlation is obtained with the minimum number of fitted parameters. On the other hand,

226 these parameters should have a physicochemical meaning, i.e. rate constant, and adsorption equilibrium constants, must increase, and decrease, respectively, with temperature, because reaction activation energy is positive and adsorption enthalpies negative.

Figure 5 shows the goodness of fit in terms of $S S R_{\min } / S S R$, where $S S R_{\min }$ is the minimum value obtained for the different models. Obviously, the model with $S S R_{\min } / S S R=1$ is the one with the minimum $S S R$, i.e. the best mathematical fit, while $S S R_{\min } / S S R$ tends to zero for worse fits. Models Class II type 4 (from now coded as II-4) with $n=1$, II-5 ( $\mathrm{n}=1$, and 2), II-6 $(n=2)$, and II-7 $(n=2)$ did not converge or led to results without physicochemical meaning during the fitting procedure. As seen in Figure 5, there are several candidate models using the mathematical criterion of minimum $S S R$, since they led to similar results. Models II-3 ( $\mathrm{n}=2)$ and I-7 $(\mathrm{n}=2)$ were the best ones, but I-5 $(\mathrm{n}=1$ and 2), II-3 (n=1), II-4 $(n=2)$, and II-6 $(n=1)$ were very close. The main characteristic of all these models stems in 238 the adsorption term. In all these models, but II-4 (n=2), $a_{w}$ participates in the denominator, so the influence of water on the reaction rate seems very clear despite they were not much sensitive to species contribution to the adsorption term, probably because composition of liquid phase was linked by the reaction stoichiometry, at least up to a point. Analyzer). As seen, particle size distributions in air and DNPE are alike, but resin beads swell about an $8 \%$ in 1-pentanol and a $35 \%$ in water. Therefore, DNPE hardly adsorbs onto the resin, but it retains $0.16 \mathrm{~mol}$ of 1-pentanol per $-\mathrm{SO}_{3} \mathrm{H}$ group (computed from data shown in Figure 6) when it is completely swollen in alcohol, and $4.2 \mathrm{~mol} \mathrm{of} \mathrm{H}_{2} \mathrm{O}$ per $247 \mathrm{SO}_{3} \mathrm{H}$ group when swollen in water. Such water amount agrees with the 3.5-3.85 mol of $248 \mathrm{H}_{2} \mathrm{O}$ per $-\mathrm{SO}_{3} \mathrm{H}$ group adsorbed when resins are in equilibrium with atmospheric air at 
$298 \mathrm{~K}^{36}$. As adsorption is exothermic, in the working temperature range of Amberlyst 70 ,

250 which is above $298 \mathrm{~K}$, it retains a smaller water amount, but it is enough to swell the resin 251 and to enable the reaction to proceed. Accordingly, it can be assumed that, at first, alcohol 252 penetrates up to some extent in the catalyst and reacts. Released water adsorbs 253 preferentially onto the resin and it swells, enabling diffusion of 1-pentanol and DNPE 254 within the catalyst. Subsequently, when there is some water in the reaction system, it 255 inhibits the reaction, as seen in Figure 4. In his turn, this fact could explain the very slow 256 reaction rates observed when wet catalyst is used instead a dry one. It is to be noted that 257 only models $\mathrm{I}-5(\mathrm{n}=1$ and $\mathrm{n}=2)$ are in agreement with these observations, since the others 258 include either the ether in the adsorption term or exclude 1-pentanol.

\subsection{Experiments with 1-pentanol/water and 1-pentanol/DNPE mixtures}

260 To stress the effect of water and DNPE on the reaction rate, a set of experiments with 1261 pentanol/water and 1-pentanol/DNPE mixtures were performed at 433 and $453 \mathrm{~K}$. Figure 7 262 plots $n_{D N P E}$ profiles along time of these experiments at $433 \mathrm{~K}$. The amount of DNPE 263 produced decreased dramatically on increasing the initial amount of water, as shown in 264 Figure 7 (up), whereas it was hardly affected when initial amounts of DNPE were added 265 (Figure 7 (down)). The same behavior was observed at 453K.

266 Figure 8 shows the effect of DNPE and water activities on the reaction rate as a function 267 of the initial w/w \% of DNPE or water in the mixture. As Figure 8 (up) shows, the effect of 268 DNPE on initial reaction rates is not remarkable. So, the weight of $a_{D}$ in the adsorption 269 term seems to be negligible. Thereafter, as reaction proceeds, the rate decreases 270 continuously on increasing $a_{D}$, and the rate-decreasing effect would be due to the progress 271 of reverse reaction. On the other hand, initial reaction rates are highly sensitive to water 272 content showing clearly its inhibiting effect (Figure 8 (down)). It is to be noted that for $a_{W} \geq$ 
0.25 reaction rate decreases very slowly, similarly to MTBE synthesis in a large methanol excess $^{37}$. This behavior could be explained by the fact that, at such water levels, reaction proceeds by a specific acid catalytic mechanism, much slower than a general one ${ }^{7}$

Models of Table 1 were fitted to the pool of experiments series done with 1-pentanol, 1pentanol/water and 1-pentanol/DNPE mixtures. Figure 9 shows the goodness of fit in terms of $S S R_{\min } / S S R$. As seen, models I-5 $(\mathrm{n}=2)$ and I-7 $(\mathrm{n}=2)$ yielded the minimum $S S R$. However, fitted values of factor $B$ in model I-7 $(\mathrm{n}=2)$ led such factor to value zero in the whole temperature range. So, the term $B \cdot a_{D}$ was removed from model I-7 $(\mathrm{n}=2)$ becoming in this way the model I-5 $(n=2)$. Then, the best kinetic model was,

$$
r_{D N P E}=\frac{A \cdot\left(a_{P}^{2}-\frac{a_{w} a_{D}}{K}\right)}{\left(a_{P}+B \cdot a_{W}\right)^{2}}
$$

By introducing water and DNPE in the initial mixture, a wider concentration and relative proportion ranges between species are achieved. This point, together with the fact that $a_{W}$ and $a_{D}$ ranges were large enough, allows us to find a rate model useful in a large reactant and product concentration range, unlike Equation 2 that only described satisfactorily the experimental results for low 1-pentanol conversions and for very small $a_{W}$ range, where influence of reverse reaction could be neglected. As a consequence, conclusions about the influence of water and DNPE could be ambiguous. Equation 8 stems from the LHHW mechanism (mechanism 1), assuming that DNPE adsorption and the fraction of free active sites are negligible. The noticeable effect of water on the reaction rate is mainly due to its competitive adsorption with 1-pentanol. Equation 8 represents satisfactorily rate data as a whole, however some deviations are observed particularly when there is a large amount of 
water in the system i.e. low reaction rates (Figure 10 up). Furthermore, the residual plot 295 shown in Figure 11 (up) is clearly biased.

\subsection{Approach by considering blocking of $-\mathrm{SO}_{3} \mathrm{H}$ groups by water}

A new approach was undertaken following the insight outlined by du Toit and $\mathrm{Nicol}^{19}$ : released water adsorbs strongly on acidic sites, it hinders 1-pentanol adsorption, and the reaction rate drops. As for LHHW or ER models, the rate constant, $\hat{k}$, is a function of the total amount of available sites. Water effect was modeled, similarly to Eq. 1, by splitting $\hat{k}$

303 Freundlich adsorption isotherm was used to consider the amount of adsorbed water, where

$304 n$ are the sites taking part in the rate-limiting step.

$$
\hat{k}=\hat{k}_{o} \cdot f\left(a_{W}, T\right)=\hat{k}_{o}\left(1-K_{W} a_{W}^{1 / \alpha}\right)^{n}
$$

$306 \quad$ where $\alpha=\frac{K_{\alpha}}{T}$

$$
\text { and } K_{W}=\frac{K_{W 1}}{T} \exp \left[-K_{W 2}\left(\frac{1}{T}-\frac{1}{\bar{T}}\right)\right]
$$

308 Models of Table 1, modified by including the correction factor defined by Equation 9, 309 were fitted to the rate data. Fitted parameters were $b$ 's from Equation $6, K_{\alpha}$ from Equation 31010 , and $K_{W 1}$ and $K_{W 2}$ from Equation 11. Therefore, three new parameters where involved in 311 the fitting procedure. The best modified kinetic model became:

$$
r=\frac{\hat{k}_{0} \cdot\left(a_{P}^{2}-\frac{a_{W} a_{D}}{K}\right)}{a_{P}}\left(1-K_{W} a_{W}^{1 / \alpha}\right)
$$


314 stems from Mechanism 2 (ER type), by assuming adsorption of DNPE and free active sites 315 being negligible. Equations 8 and 12 have the same driving force and include 1-pentanol in 316 the adsorption term. The difference between both models is the role attributed to water. 317 Equation 8 assumes a strong competitive water adsorption lessening the global reaction 318 rate, whereas Equation 12 supposes that a part of released water remains in the catalyst 319 blocking or inhibiting the active centers, what has a reducing effect on the global rate 320 constant value.

321 Table 2 shows the values of fitted parameters of Equations 8 and 12, and their standard 322 errors, estimated by a variation of Jackknife method ${ }^{38}$. As can be seen, Equation 12 yielded 323 a better fit than Equation 8, with a decrease of the $S S R$ of about $42 \%$ and, as a result, a 324 more reliable value of the estimated reactions rate is obtained (Figure 10 down). Fitting 325 improvement could be attributed to the fact that Equation 12 has one more parameter to fit 326 than Equation 8, and/or that the power-type expression for water adsorption is flexible enough to properly fit rate data. Apparent activation energies of 1-pentanol dehydration to DNPE estimated from the variation of the rate constant on temperature were very similar 329 for both models, taking into account that Jakknife method underestimates standard error. 330 This would imply that water adsorption hardly influences the sensitivity of the reaction rate 331 to temperature. It is to be noted that both values are similar to that obtained from 332 experiments with no initial feed of water fitted to Equation $2(115 \pm 6 \mathrm{~kJ} / \mathrm{mol})^{27}$.

333 Figure 12 plots the values of correction factor, $1-K_{W} a_{W}^{1 / \alpha}$, as used in Equation 12 versus $334 a_{W}$ in the whole temperature range. The correction factor decreases on increasing 335 temperature and $a_{W}$, therefore its effect is higher. It is to be noted that trends of correction 
factor and $r_{D N P E}$ are alike for $a_{W} \leq 0.25$ for those experiments performed with an initial

337 amount of water (see Figure 8). For larger $a_{w}$ values, reaction rates tend to a plateau which 338 is a function of initial water content, whereas the correction factor decreases monotonically. 339 This could be because Freudlich isotherm is generally valid for low or intermediate species 340 activities. On the other hand, it is expected that $\alpha$ decrease almost linearly with temperature, 341 and $K_{w}$ to be roughly non dependent ${ }^{19,39}$. Moreover $\alpha$ should be higher than unity. From $K_{\alpha}$, $342 K_{W 1}$ and $K_{W 2}$ values it is seen that (a) $\alpha$ decreases with temperature, but it is lower than 343 unity, and (b) $K_{W}$ value at $463 \mathrm{~K}$ is nearly twice that of at $413 \mathrm{~K}$. These points suggest that 344 the fitting improvement is due to the flexibility of the power expression for $\theta_{W}$ and to the 345 fact that the fitting procedure involved more parameters rather than to a fundamental 346 insight of Freundlich isotherm. Thus, the kinetic model proposed by Equation 12 is a 347 pseudo-empirical model rather than a mechanistic one. However, if the correction factor is 348 considered in terms of catalyst deactivation, $K_{W}$ could be considered as a deactivation 349 constant. Consequently, from its temperature dependence a pseudo-activation energy for 350 the water deactivation process of $24.7 \pm 0.1 \mathrm{~kJ} / \mathrm{mol}$ could be computed.

351 In Table 3, cross-correlation matrices of the fitted parameters for both Equation 8 and 12 352 are shown. Equation 12 presents a more desirable cross-correlation matrix, as all values 353 other than diagonal are close to 0 . In addition, as seen in Figure 11 residuals distribution for 354 Equation 12 is nearly random, whereas, in the case of Equation 8, a clearly biased residual 355 plot is observed.

356 The kinetic model proposed by Equation 8 is clearly a mechanistic one (LHHW 357 mechanism), so it could be extrapolated to other operational conditions. On the other hand, 358 the modified kinetic model proposed by Equation 12 (derived from a ER mechanism) 
explains better the results presented in this work, but due to its pseudo-empirical

360 background the extrapolation should be done with precaution.

\section{Conclusions}

Two kinetic models are proposed to explain the dehydration of 1-pentanol to DNPE in the liquid-phase. Firstly, a classical LHHW model is proposed, based on a mechanism in which the surface reaction between two adsorbed molecules of 1-pentanol is the ratelimiting step with a significant contribution of 1-pentanol and water adsorption in the denominator. On the other hand, a modified ER model is proposed, based on a mechanism in which the surface reaction between one molecule of 1-pentanol from the bulk phase and one adsorbed 1-pentanol molecule is the rate-limiting step, with a significant contribution

369 of 1-pentanol in the denominator. The inhibiting effect of water is taken into account with a 370 factor that modifies the actual intrinsic rate constant, in which a Freundlich-like adsorption 371 isotherm is used. Both models fitted data satisfactorily, although the best results were 372 obtained with the modified model. The activation energy was $118.7 \pm 0.2 \mathrm{~kJ} / \mathrm{mol}$ for the 373 LHHW model and $114.0 \pm 0.1 \mathrm{~kJ} / \mathrm{mol}$ for the modified one. These values are very similar 374 to the obtained when experiments with initial water and DNPE were not included in the 375 fitting procedure.

\section{$376 \quad$ Acknowledgements}

377 Authors are thankful for financial support from State Education, Universities, Research 378 \& Development Office of Spain (Projects PPQ2000-0467-P4-02 and CTQ2004379 01729/PPQ). Authors are also grateful to Rohm and Haas for providing the ion-exchange 380 resin catalyst used in this work

\section{$381 \quad$ Nomenclature}

$$
a_{j} \quad \text { activity of compound } \mathrm{j}
$$


$383 A, B, C, k_{1}$ grouped factors for fitting purposes

$384 \quad b_{i} \quad$ fitted parameters

$385 \quad \hat{k} \quad$ intrinsic rate constant $\left(\mathrm{mol} \mathrm{h}^{-1} \mathrm{~g}^{-1}\right)$

$386 \quad \hat{k}_{0} \quad$ intrinsic rate constant without the effect of water $\left(\mathrm{mol} \mathrm{h}^{-1} \mathrm{~g}^{-1}\right)$

$387 \quad K_{j} \quad$ adsorption equilibrium constant of $\mathrm{j}$

$388 \quad K \quad$ thermodynamic equilibrium constant

$389 \quad K_{\alpha}, K_{w} \quad$ Freundlich-type correction factor constants

$390 \quad n \quad$ number of active sites involved in the surface reaction

$391 \quad n_{D N P E} \quad$ number of DNPE moles

$392 \quad r_{D N P E} \quad$ reaction rate of DNPE synthesis $\left(\mathrm{mol} \mathrm{h}^{-1} \mathrm{~kg}^{-1}\right)$

$393 \quad T \quad$ temperature $(\mathrm{K})$

$394 \quad \bar{T} \quad$ mean experimental temperature $(\mathrm{K})$

$395 \quad$ catalyst mass $(\mathrm{g})$

$396 \quad$ Greek letters

$397 \quad \theta_{W} \quad$ fraction of active centers occupied by water

$398 \quad$ Subscripts

399 D DNPE, di-n-pentyl ether

$400 \quad \mathrm{P} \quad$ 1-pentanol

401 W water

402 


\section{Literature Cited}

404 (1) Cunill, F.; Vila, M.; Izquierdo, J.F.; Iborra, M.; Tejero, J. Effect of Water Presence on 405 Methyl tert-Butyl Ether and Ethyl tert-Butyl Ether Liquid Phase Syntheses. Ind. Eng. Chem.

406

407

408

409

410

411

412

413

414

415

416

417

418

419

420

421

422

423

424 Res. 1993, 32, 564-569.

(2) Cruz, V.J.; Bringué, R.; Cunill, F.; Izquierdo, J.F.; Tejero, J.; Iborra, M.; Fité, C. Conversion, selectivity and kinetics of the liquid-phase dimerisation of isoamylenes in the presence of $\mathrm{C} 1$ to $\mathrm{C} 5$ alcohols catalysed by a macroporous ion-exchange resin. J. Catal. 2006, 238, 330-341.

(3) Honkela, M.; Krause, A.O.I. Kinetic modeling of the dimerization of isobutene. Ind. Eng. Chem. Res. 2004, 43, 3251-3260.

(4) Talwalkar, S.; Chauhan, M.; Aghalayam, P.; Qi, Z.; Sundmacher, K.; Mahajani, S.M. Kinetic studies on the dimerization of isobutene with ion-exchange resin in the presence of water as a selective enhancer. Ind. Eng. Chem. Res. 2006, 45, 1312-1323.

(5) Thotla, S.; Agarwal, V.; Mahajani, S.M. Aldol condensation of acetone with reactive distillation using water as a selectivity enhancer. Ind. Eng. Chem. Res. 2007, 46, 83718379.

(6) Jerabek, K.; Onoha, J.; Setinek, K. Kinetics of the synthesis of Bisphenol A. Appl. Catal. 1988, 37, 129-138

(7) Gates, B.; Rodriguez, W. General and specific acid catalysis in sulfonic acid resins. J. Catal. 1973, 31, 27-31.

(8) Reinicker, R.A.; Gates, B.C.; Bisphenol A Synthesis: kinetics of the phenol-acetone condensation reaction catalyzed by sulfonic acid reaction, AIChE J. 1974, 20, 933-940.

(9) Teo, H.T.R.; Saha, B. Heterogeneous catalysed esterification of acetic acid with isoamylalcohol: kinetic studies. J. Catal. 2004, 228, 174-182. 
(10) Aiouache, F.; Goto, S. Sorption effect on kinetics of etherification of tert-amyl 428 alcohol and ethanol. Chem. Eng. Sci. 2003, 58, 2065-2077.

429 (11) Aragon, J.M.; Vegas, J.M.R.; Jodra, L.G. Catalytic Behavior of Macroporous 430 Resins in Catalytic Processes with water production. Activation and inhibition effects in the 431 kinetics of the self-condensation of cyclohexanone. Ind. Eng. Chem. Res. 1993, 32, 25554322562.

433 (12) Lee, M.J.; Wu, H.T.; Lin, H.M. Kinetics of catalytic esterification of acetic acid and 434 amyl alcohol over Dowex. Ind. Eng. Chem. Res. 2000, 39, 4094-4099.

435 (13) Liu, W.T.; Tan, C.S. Liquid-phase esterification of propionic acid with n-butanol. 436 Ind. Eng. Chem. Res. 2001, 40, 3281-3286.

437 (14) Lee, M.J.; Chiu, J.Y.; Lin, H.M. Kinetics of catalytic esterification of propionic 438 acid and n-butanol over Amberlyst 35. Ind. Eng. Chem. Res. 2002, 41, 2882-2887.

439 (15) Kawase, M.; Inoue, Y.; Araki, T.; Hashimoto, K. The simulated moving-bed reactor 440 for production of bisphenol A. Catal. Today. 1999, 48, 199-209.

441 (16) Podrebarac, G.G.; Ng, F.T.T.; Rempel, G.L. A kinetic study of the aldol 442 condensation of acetone using an anion exchange resin catalyst, Chem. Eng. Sci. 1997, 52 443 (17), 2991-3002.

444 (17) Yang, B.L.; Maeda, M.; Goto, S. Kinetics of Liquid Phase Synthesis of tert-Amyl 445 Methyl Ether from tert-Amyl Alcohol and Methanol Catalyzed by Ion Exchange Resin. Int. $446 \quad$ J. Chem. Kinet. 1998, 30 (2), 137-143.

447 (18) Limbeck, U.; Altwicker, C.; Kunz, U.; Hoffmann, U. Rate Expression for THF 448 synthesis on acidic ion exchange resin. Chem. Eng. Sci. 2001, 56, 2171-2178. 
(19) du Toit, E.; Nicol, W. The rate inhibiting effect of water as a product on reactions 450 catalysed by cation exchange resins: formation of mesityl oxide from acetone as case study. 451 Appl. Catal. A: General. 2004, 277, 219-225.

452 (20) Gates BC. Catalytic Chemistry. New York : Wiley, 1992, 182-253.

453 (21) Chakrabarti, A.; Sharma, M.M. Cationic Exchange resins as catalysts. React. 454 Polym. 1993, 20 (1-2), 1-45.

455 (22) Hoek, I.; Nijhuis, T.A.; Stankiewicz, A.I.; Moulijn, J.A. Kinetics of solid acid 456 catalyzed etherification of symmetrical primary alcohols: Zeolite BEA catalyzed 457 etherification of 1-octanol. Appl. Catal. A: General. 2004, 266, 109-116.

458 (23) Aiouache, F.; Goto, S. Kinetic study on 2-methyl-1-butanol dehydration catalysed 459 by ion exchange resin. J. Chem. Eng. Japan. 2002, 35, 436-442.

460 (24) Sow, B.; Hamoudi, S.; Zahedi-Niaki, M.H.; Kaliaguine, S. 1-Butanol etherification 461 over sulfonated mesostructured silica and organo-silica, Micro. Meso. Materials. 2005, 79, $462 \quad 129-136$.

463 (25) Castor González, J.; Fair, J.R. Preparation of tertiary amyl alcohol in a reactive 464 distillation column. 1. Reaction kinetics, chemical equilibrium, and mass transfer issues. 465 Ind. Eng. Chem Res. 1997, 36, 3833-3844.

466 (26) Tejero, J.; Cunill, F.; Iborra, M.; Izquierdo, J.F.; Fité, C. Dehydration of 1-pentanol 467 to di-n-pentyl ether on ion-exchange resin catalysts, J. Mol. Cat. A: Chem. 2002, 182-183, $468 \quad 541-554$.

469 (27) Bringué, R.; Iborra, M.; Tejero, J.; Izquierdo, J.F.; Cunill, F.; Fite, C.; Cruz, V.J. 470 Thermally stable ion-exchange resins as catalysts for the liquid-phase dehydration of 1471 pentanol to di-n-pentyl ether (DNPE). J. Catal. 2006, 244, 33-42. 
(28) Bringué, R.; Tejero, J.; Iborra, M.; Izquierdo, J.F.; Fité, C.; Cunill, F. Experimental 473 Study of Chemical Equilibria in the Liquid-Phase Dehydration of 1-Pentanol to di-n-pentyl ether. Ind. Eng. Chem. Res. 2007, 46, 6865-6872.

(29) Bringué, R.; Tejero, J.; Iborra, M.; Izquierdo, J.F.; Fité, C.; Cunill, F. Water effect on the kinetics of 1-pentanol dehydration to di-n-pentyl ether (DNPE) on Amberlyst 70. Top. Catal. 2007, 45 (1-4), 181-186.

(30) Medina, E. MS Chemical Engineering Thesis. University of Barcelona. 2007

(31) Wittig, R.; Lohmann, J.; Gmehling, J. Vapor-Liquid Equilibria by UNIFAC Group Contribution. 6. Revision and Extension. Ind. Eng. Chem. Res. 2003, 42, 183-188.

(32) Tejero, J.; Cunill, F.; Izquierdo, J.F. Vapor-Phase Addition of Methanol to Isobutene on a Macroporous Resin. A Kinetic Study. Ind. Eng. Chem. Res. 1989, 28, 1269-1277.

(33) Iborra, M.; Izquierdo, J.F.; Cunill, F.; Tejero, J. Application of the Response Surface Methodology to the Kinetic Study of the Gas-Phase Addition of Ethanol to Isobutene on a Sulfonated Styrene-Divinylbenzene Resin. Ind. Eng. Chem. Res. 1992, 31, 1840-1848.

(34) Cunill, F.; Tejero, J.; Fité, C.; Iborra, M.; Izquierdo, J.F. Conversion, Selectivity, and Kinetics of the Dehydration of 1-Pentanol to di-n-Pentyl ether Catalyzed by a Microporous Ion-Exchange Resin. Ind. Eng. Chem. Res. 2005, 44, 318-324.

(35) Tejero, J.; Cunill, F.; Iborra, M.; Izquierdo, J.F.; Fité, C.; Bringué, R. Liquid-phase dehydration of 1-pentanol to di-n-pentyl ether (DNPE) over medium and large pore acidic zeolites. Micro. Meso. Materials 2009, 117 (3), 650-660.

(36) Iborra, M.; Tejero, J.; Cunill, F.; Izquierdo, J.F.; Fité, C. Drying of Acidic Macroporous Styrene-Divinylbenzene Resins with 12-20\% Crosslinking Degree. Ind. Eng. Chem. Res. 2000, 39 (5), 1416-1422. 
496 addition of alcohol to olefins. J. Catal. 1977, 46, 49-57.

497 (38) Caceci, M.S. Estimating error limits in parametric curve fitting. Anal. Chem. 1989, $498 \quad 61,2324-2327$.

499 (39) Adamson, A.W. Physical Chemistry of Surface, Fifth Edition Wiley, New York. $5001990,421-426$

501

502 
504 Figure 1. Effect of resin particle size on DNPE production (up) and the initial reaction 505 rate (down) at $463 \mathrm{~K}, \mathrm{~N}=500 \mathrm{rpm}, 1 \mathrm{~g}$ dry Amberlyst 70 .

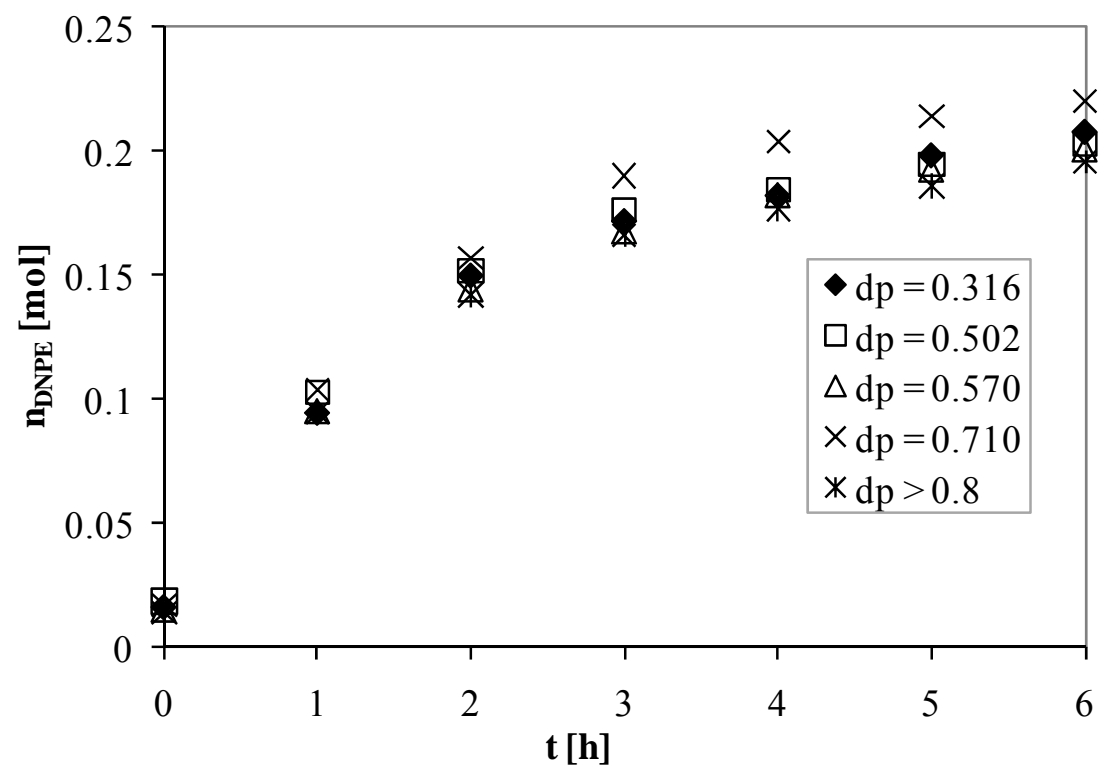

506

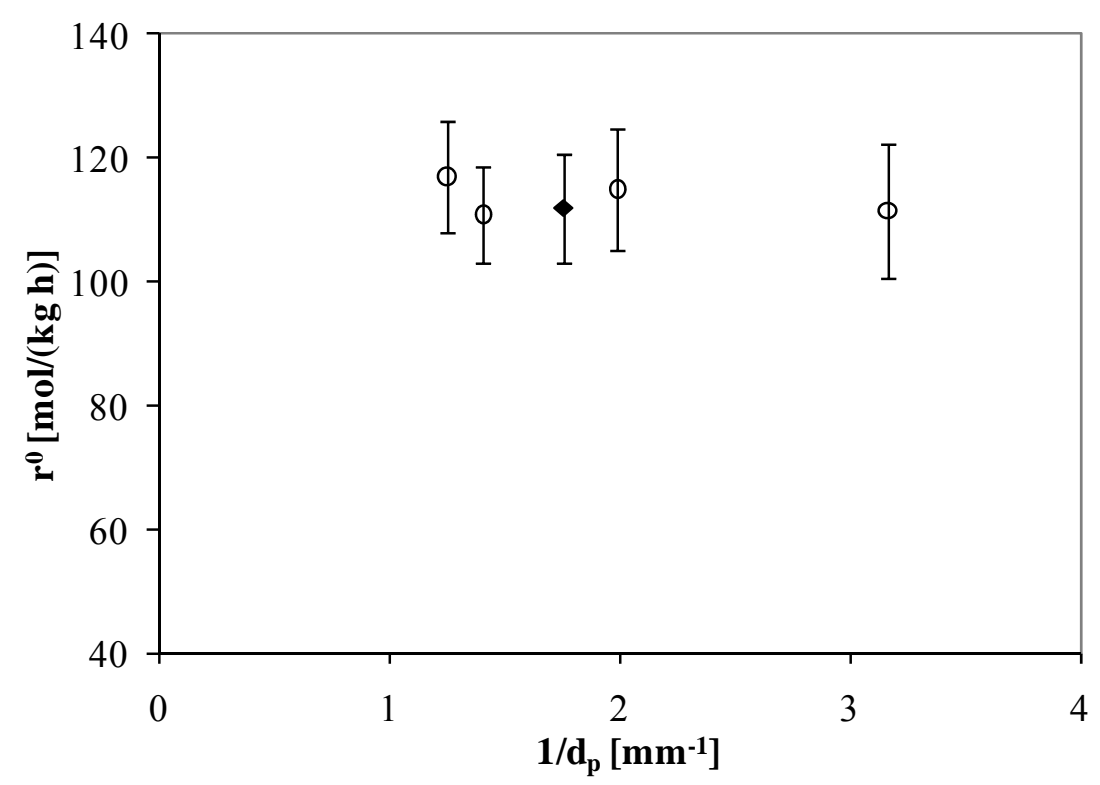


511 (down) at 463K, $1 \mathrm{~g}$ of dried commercial beads of Amberlyst 70.

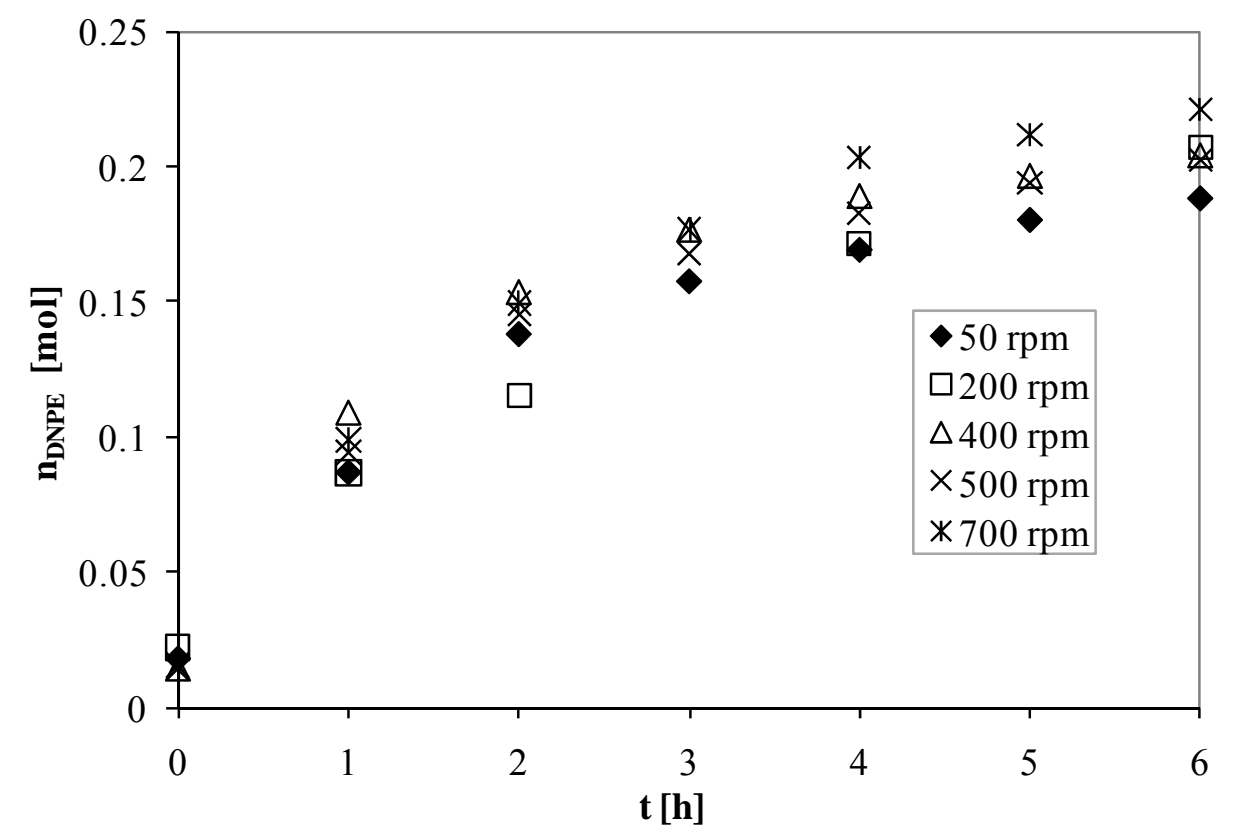

512

513

514

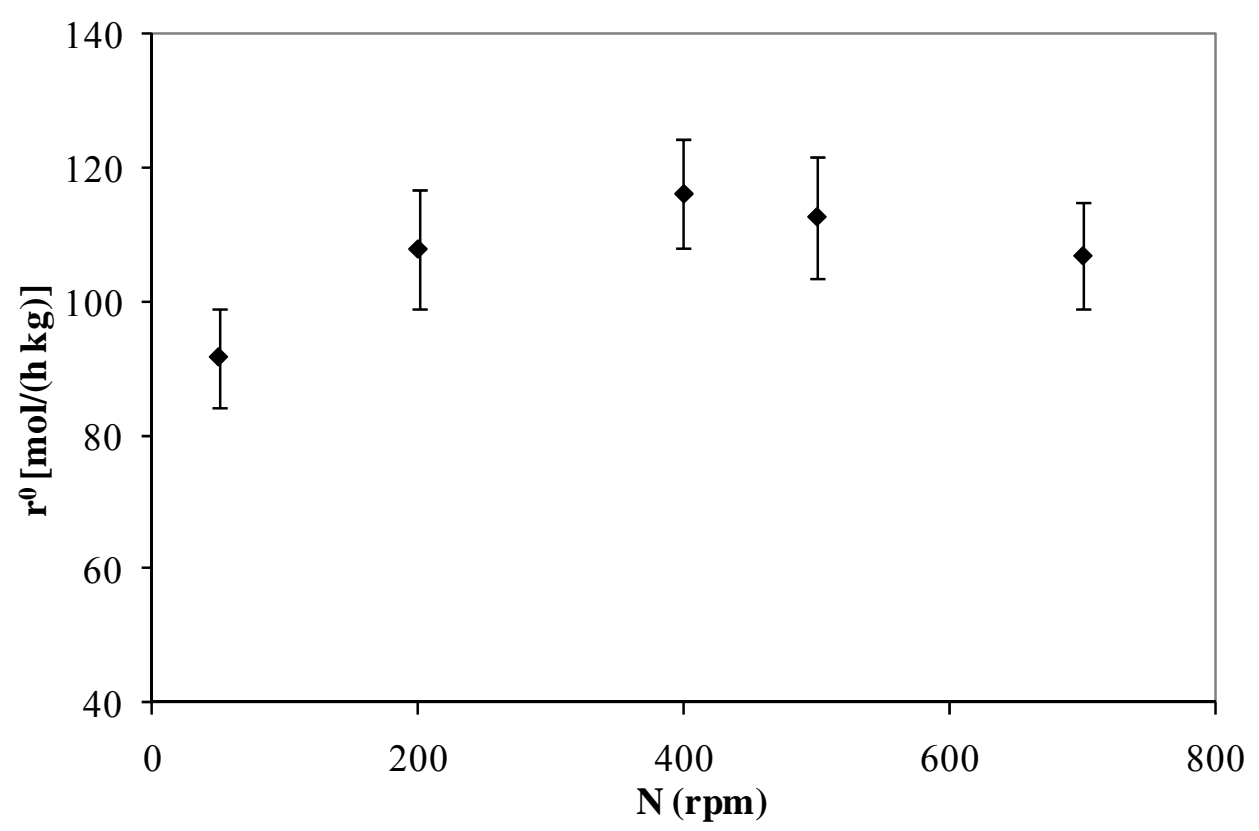


516 Figure 3. DNPE mole profile versus time at temperatures tested.

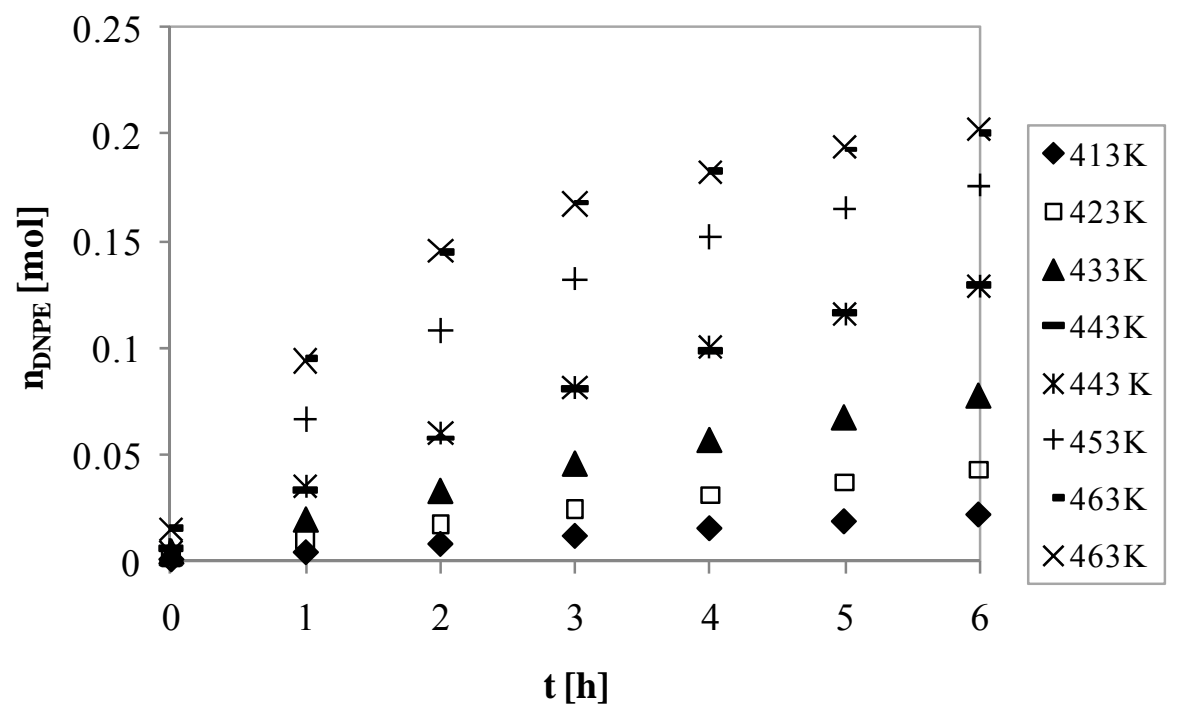

518 
519 Figure 4. Reaction rate of DNPE synthesis as a function of 1-pentanol (up), DNPE

520 (middle) and water (down) activities in the temperature range explored

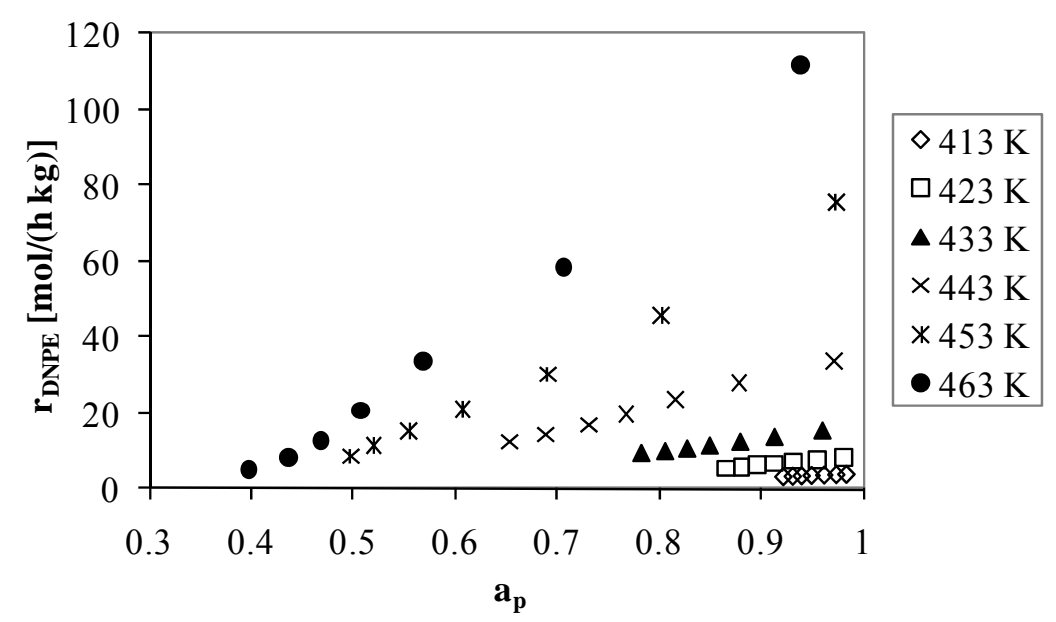

521

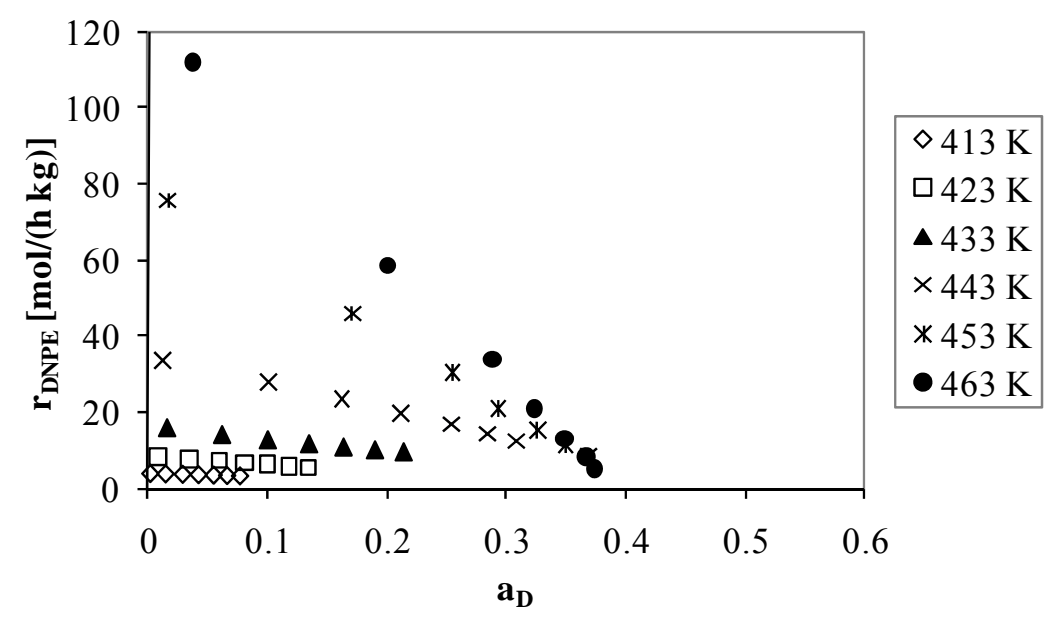




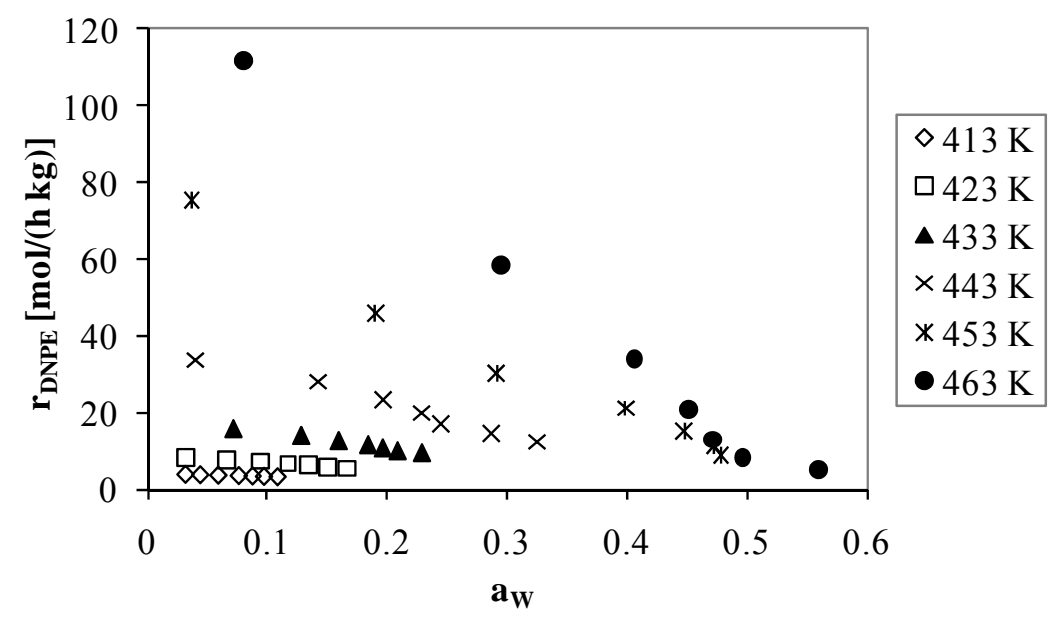

523 
525 Figure 5. Comparison of the goodness of fit in terms of $S S R_{\min } / S S R$.

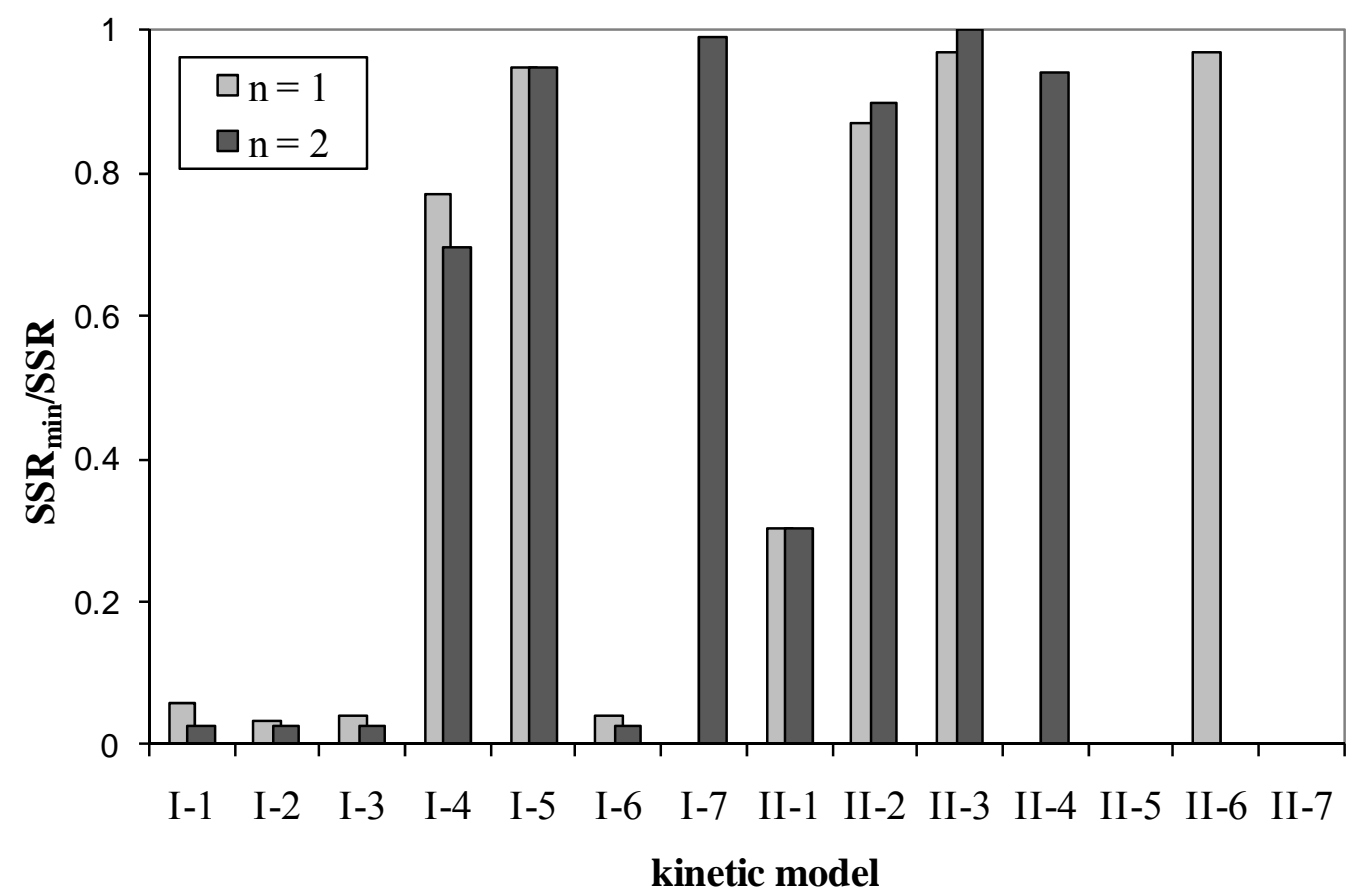


528 Figure 6. Particle size distribution in dry air, 1-pentanol, DNPE and water for Amberlyst 52970.

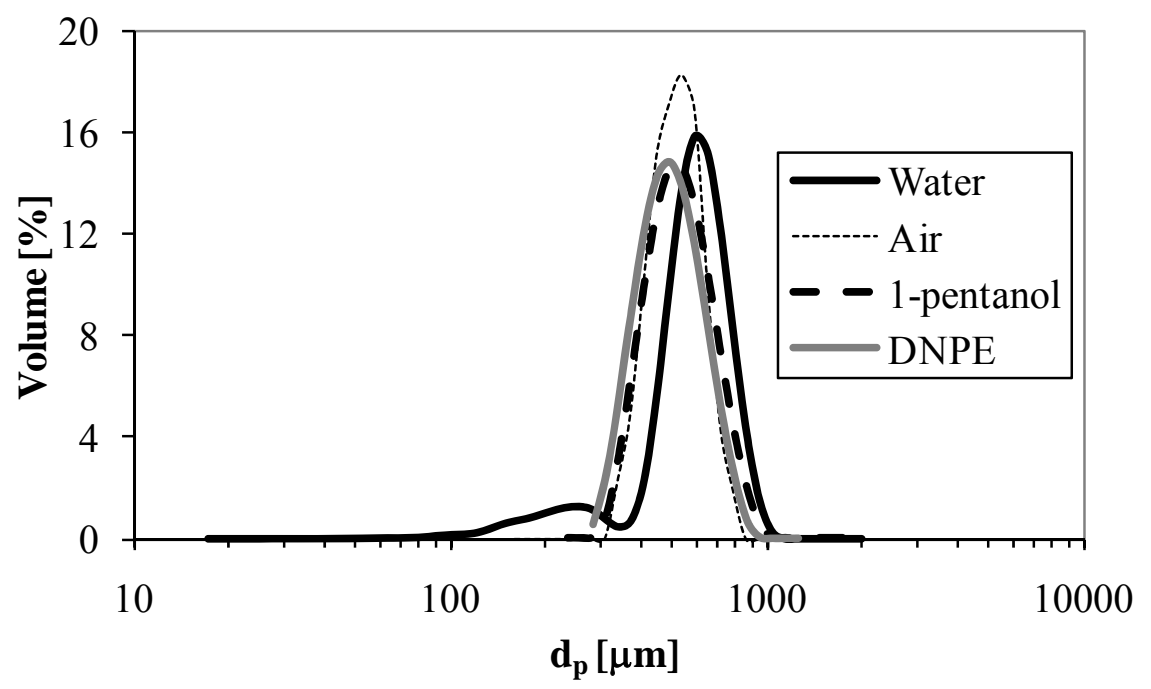

530 
533 DNPE (down) in the initial mixture at $433 \mathrm{~K}$

534

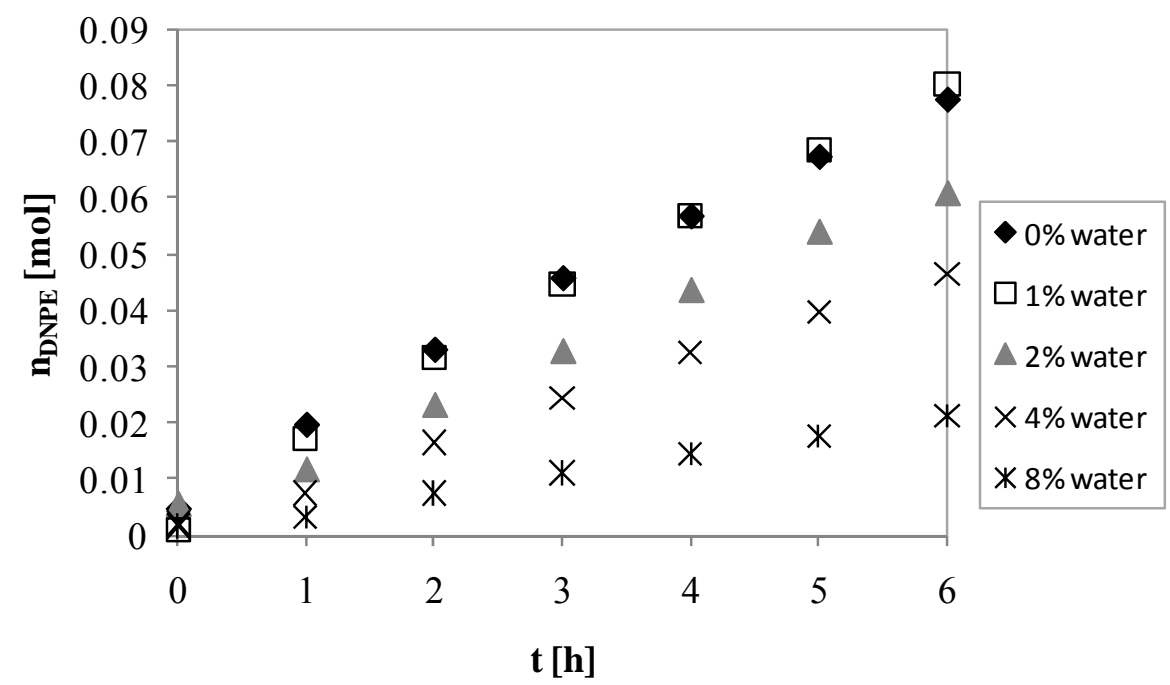

535

536

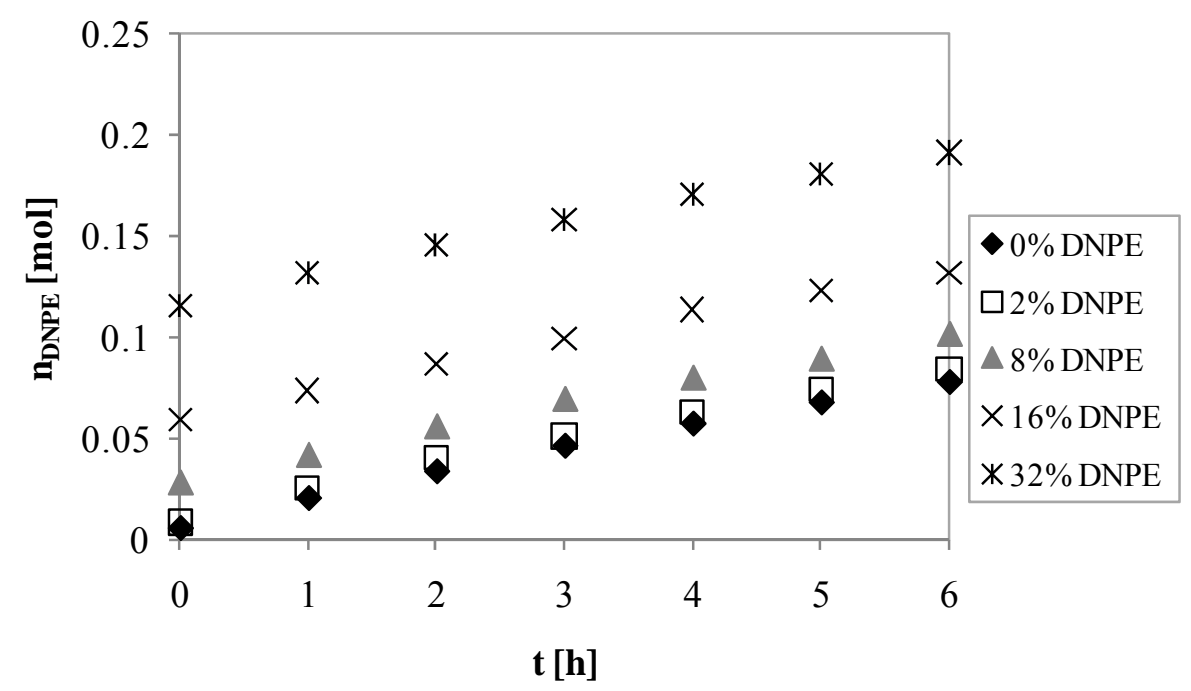

537

538 
539 Figure 8. Effect of DNPE (up) and water (down) activities on the reaction rate at $433 \mathrm{~K}$ 540 at different initial mixtures 1-pentanol/water and 1-pentanol/DNPE (Dotted lines join initial 541 reaction rate data)

542

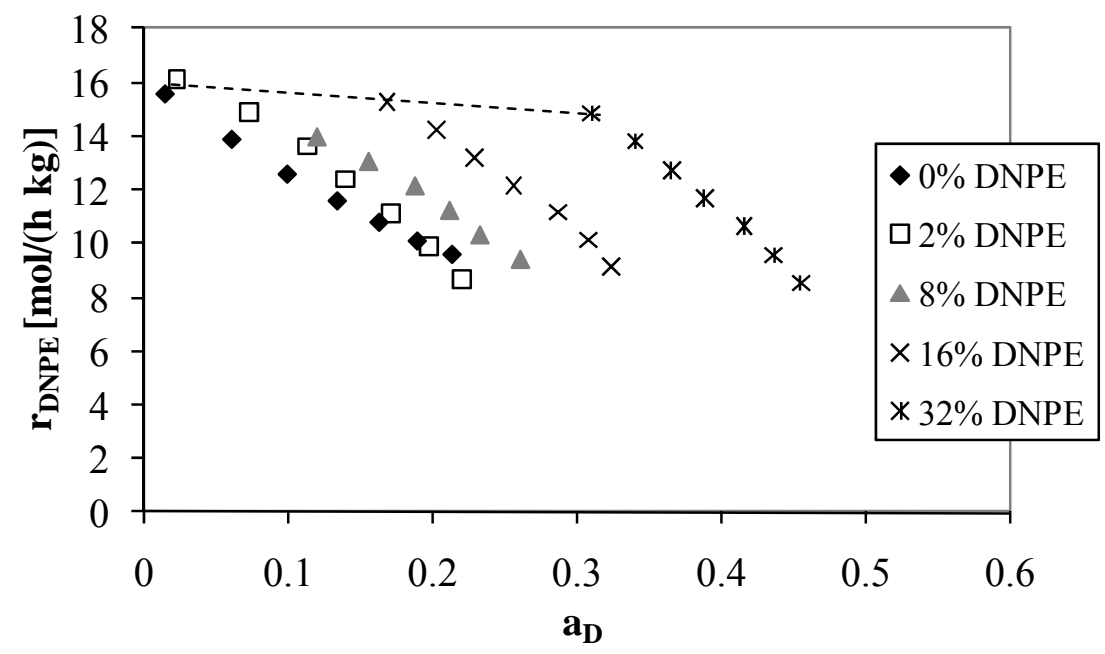

543

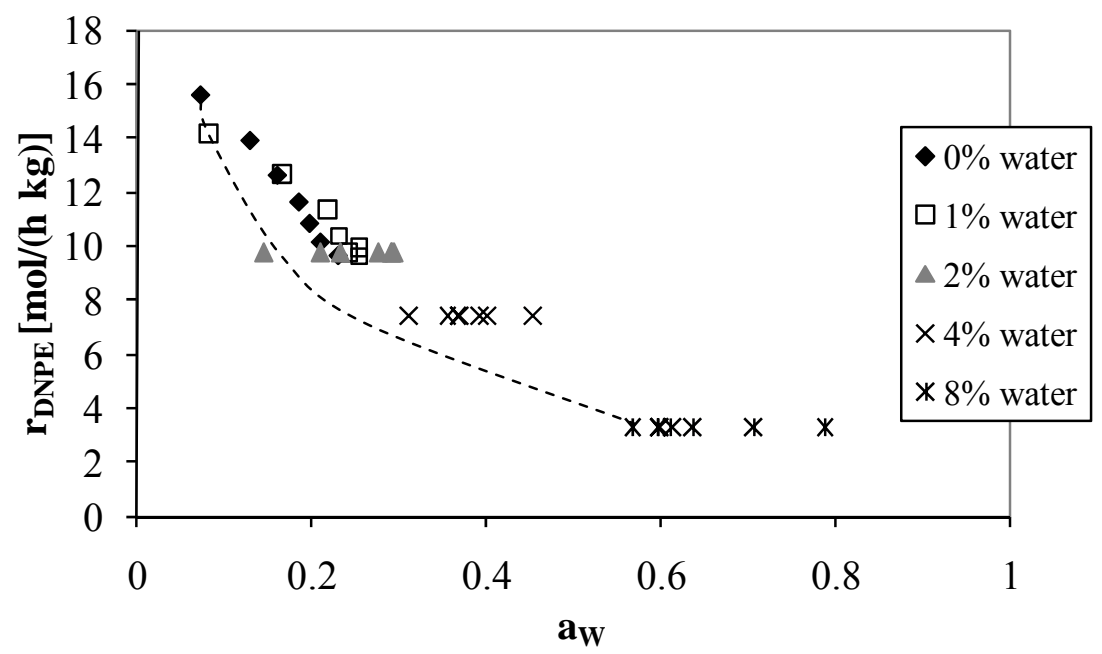

544 
547 Figure 9. Comparison of goodness of fit in terms of $S S R_{\min } / S S R$ when including 548 experiments with initial amounts of water and DNPE.

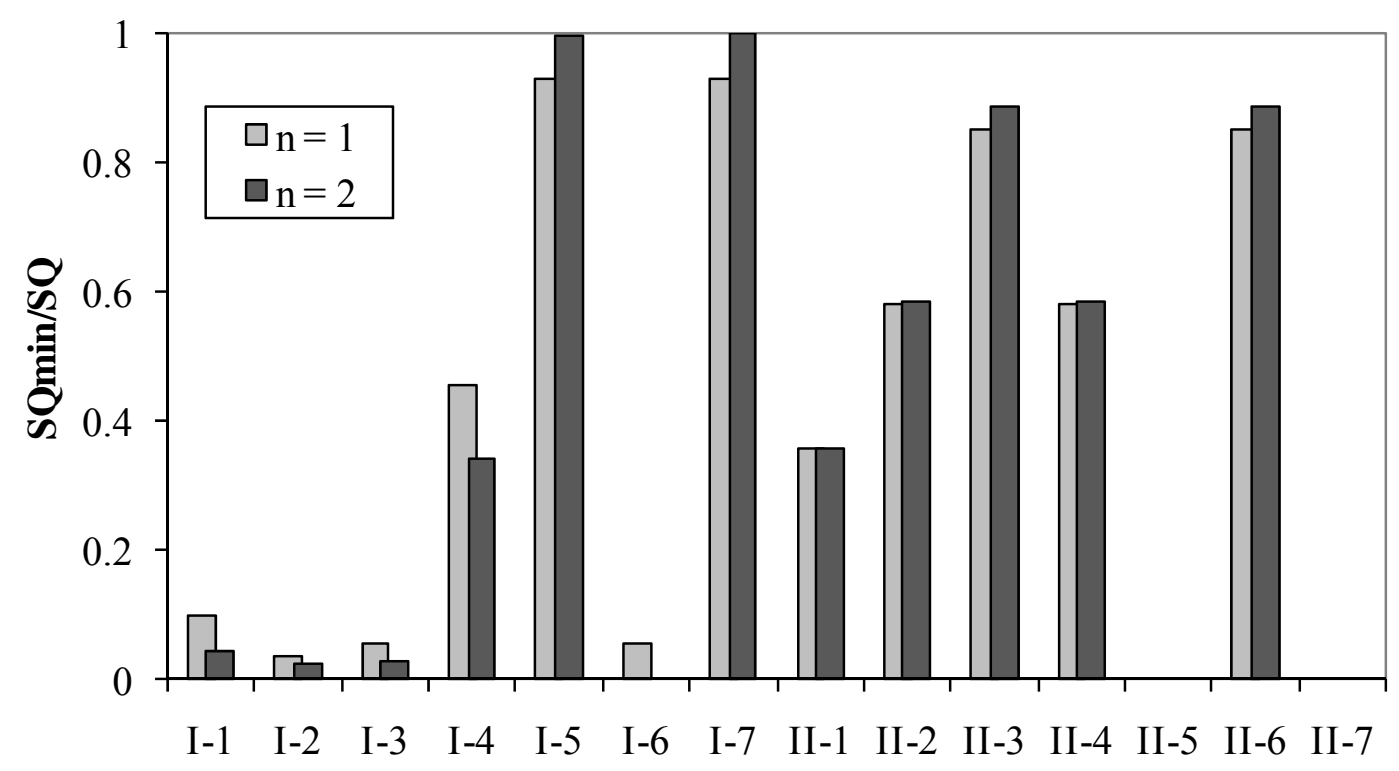

\section{kinetic model}

549 
551 Figure 10. Calculated reaction rates by Equation 8 (up) and by Equation 12 (down)

552 versus experimental rates in the whole temperature range

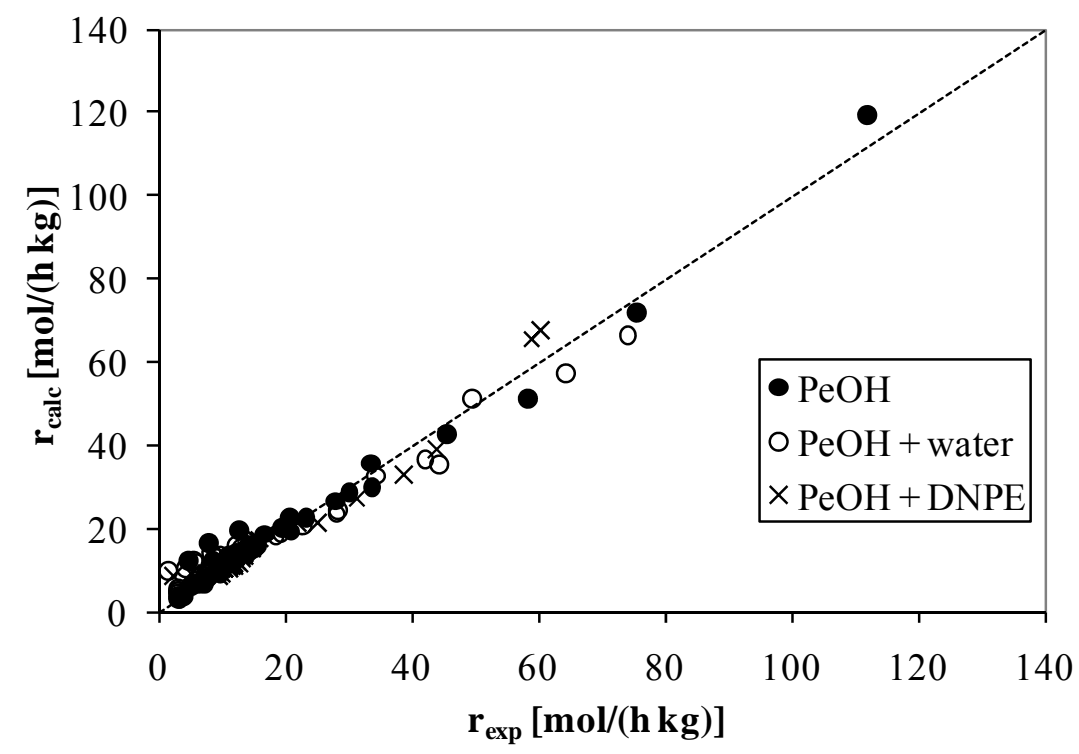

553

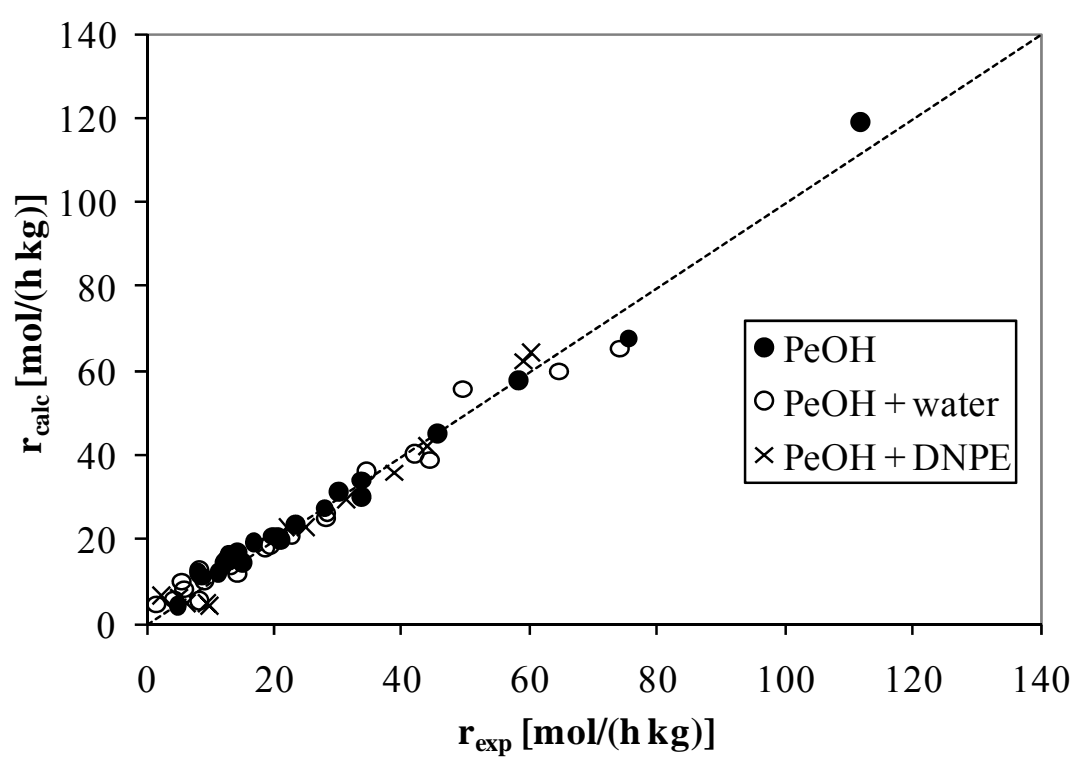

554 
Figure 11. Residuals distribution for Equation 8 (up) and Equation 12 (down).

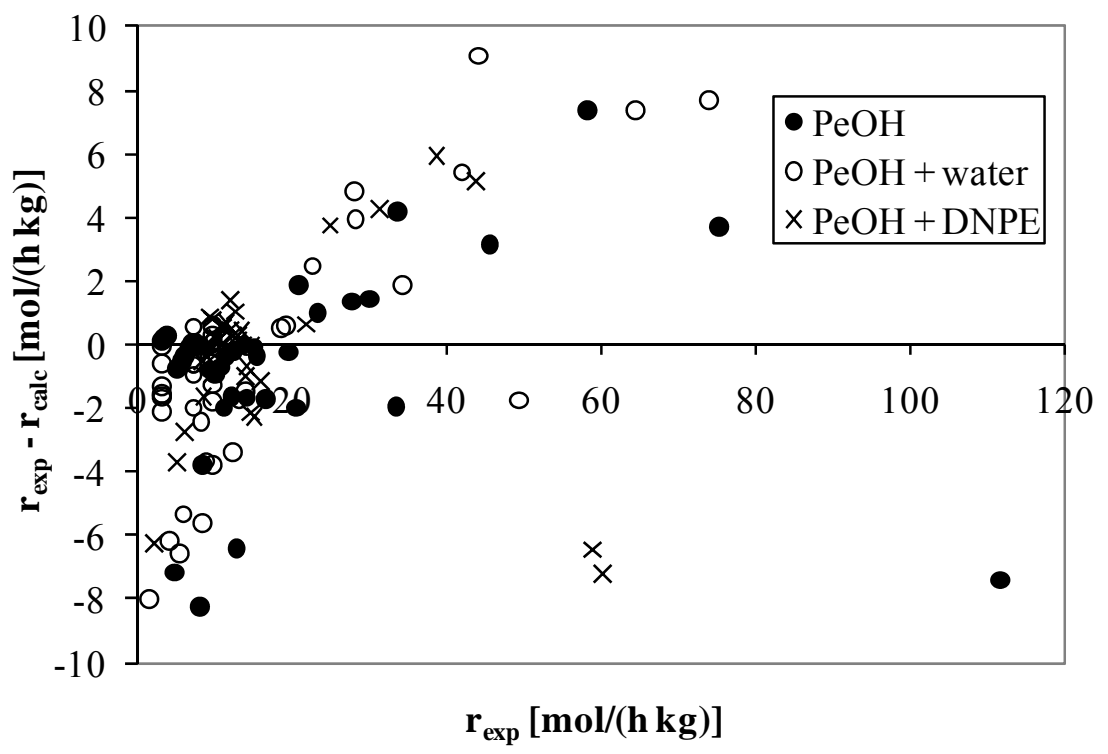

559

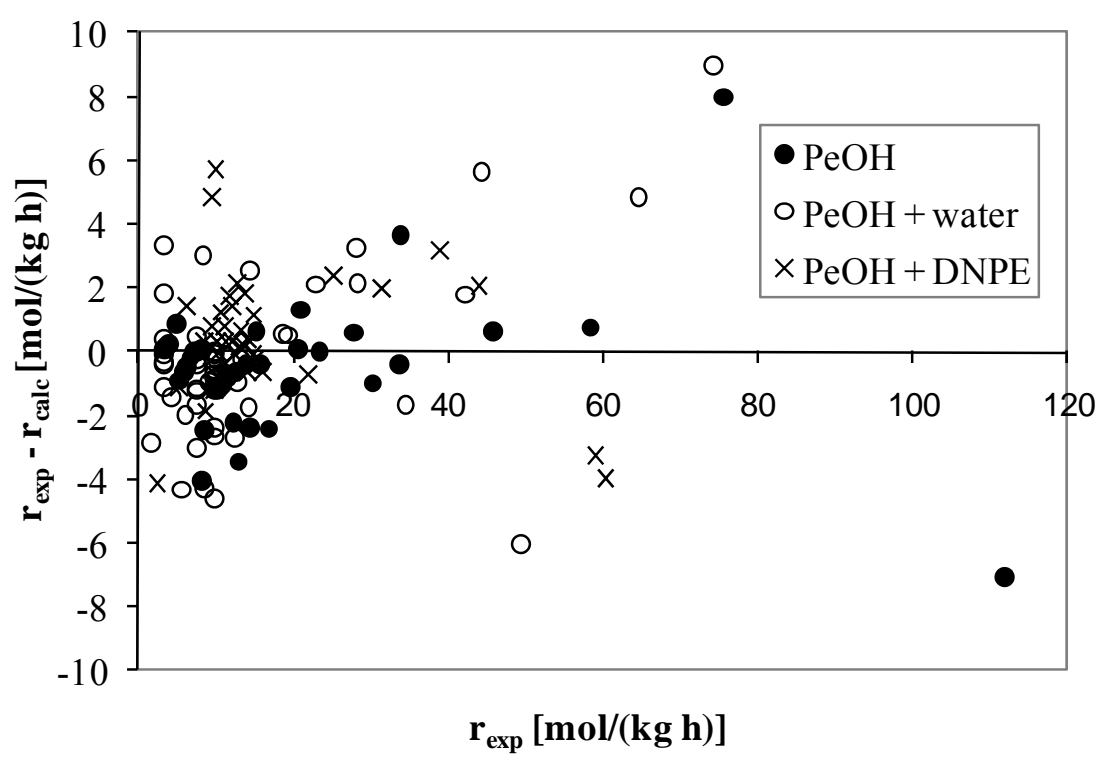

560 
562 Figure 12. Computed correction factor versus $a_{w}$ in the whole temperature range

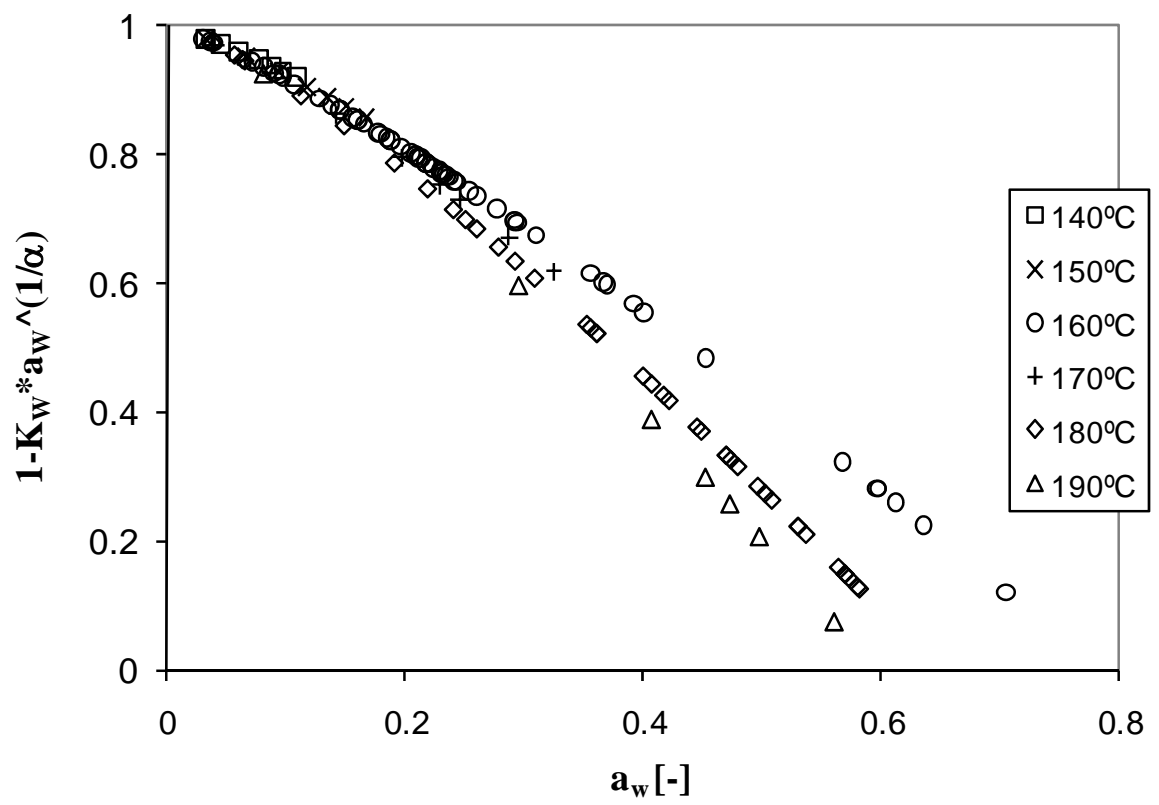

563 
566 Table 1. Kinetic models tested with $n$ values ranging from 1 to 2

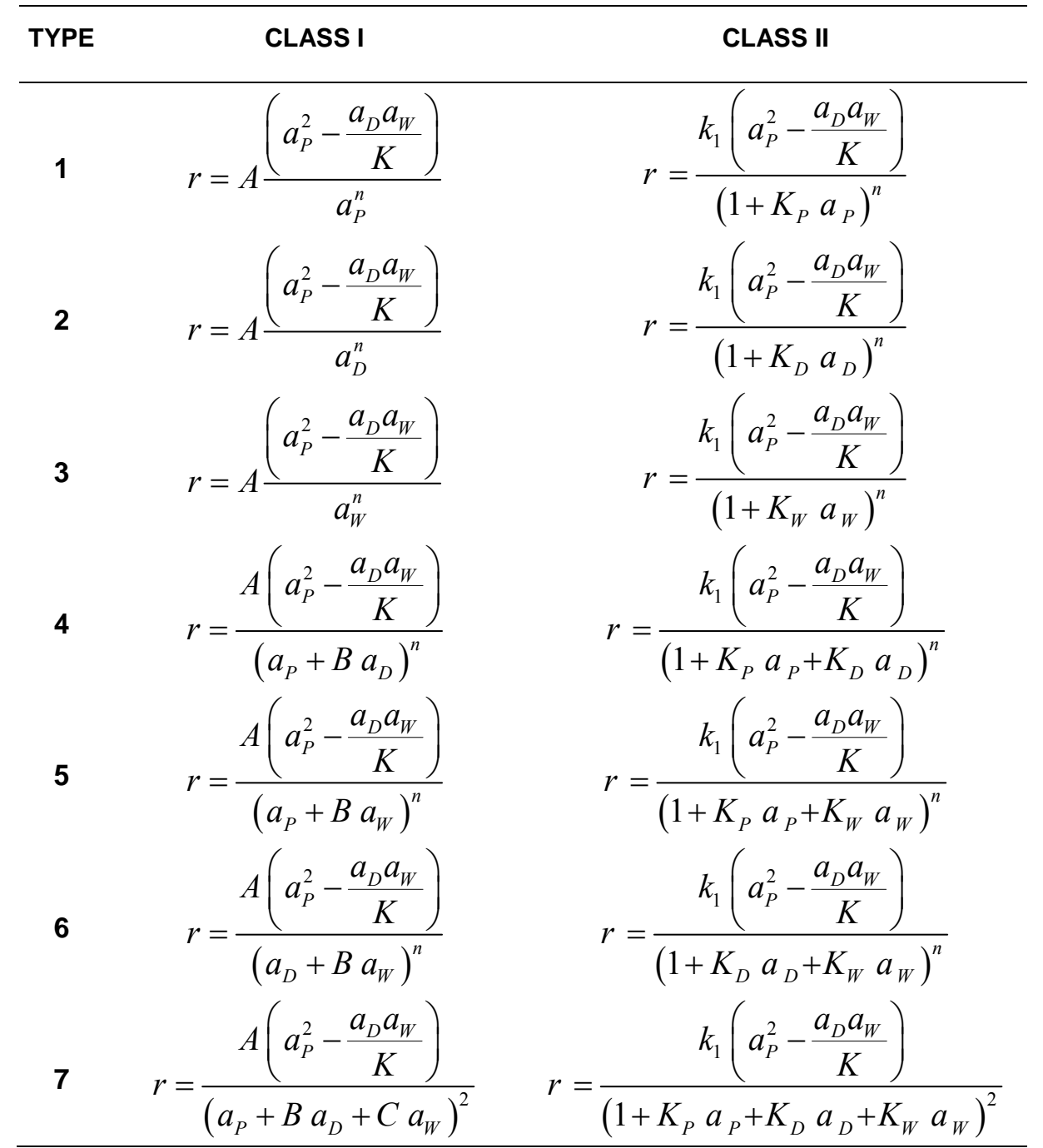


$570 \mathrm{~A}$ and $\mathrm{b}_{3}$ and $\mathrm{b}_{4}$ to $\mathrm{B}$, according to Equation 6) and $12\left(\mathrm{~b}_{1}\right.$ and $\mathrm{b}_{2}$ corresponding to $\left.\hat{k}_{0}\right)$

\begin{tabular}{ccc}
\hline & Equation 8 & Equation 12 \\
\hline $\mathrm{b}_{1}$ & $2.160 \pm 0.003$ & $2.122 \pm 0.002$ \\
$\mathrm{~b}_{2}$ & $14275 \pm 25$ & $13710 \pm 15$ \\
$\mathrm{~b}_{3}$ & $0.007 \pm 0.006$ & \\
$\mathrm{~b}_{4}$ & $2952 \pm 38$ & \\
$\mathrm{~K}_{\mathrm{w} 1}$ & & $495 \pm 4$ \\
$\mathrm{~K}_{\mathrm{w} 2}$ & & $2971 \pm 49$ \\
$\mathrm{~K}_{\alpha}$ & & $358 \pm 1$ \\
$\mathrm{E}_{\mathrm{a}}(\mathrm{kJ} /$ mol $)$ & $118.7 \pm 0.2$ & $114.0 \pm 0.1$ \\
SSR & 1190 & 690 \\
SSR variation over Equation $8(\%)$ & 0 & -42 \\
\hline
\end{tabular}

571 
Table 3. Correlation matrix of fitted parameters for Equation $8\left(b_{i}\right.$ are the fitting

574 parameters of factors $\mathrm{A}$ and $\mathrm{B}$ of the model) and Equation12 $\left(b_{i}\right.$ and $K_{W i}$ are the fitting

575 parameters of factors $\mathrm{A}$ and $K_{W}$ of the model), respectively.

\begin{tabular}{|c|c|c|c|c|c|}
\hline \multicolumn{5}{|c|}{ Equation 8} & \\
\hline & $b_{1}$ & $\mathrm{~b}_{2}$ & $b_{3}$ & $\mathrm{~b}_{4}$ & \\
\hline$b_{1}$ & 1 & & & & \\
\hline $\mathrm{b}_{2}$ & -0.97 & 1 & & & \\
\hline$b_{3}$ & 0.85 & -0.78 & 1 & & \\
\hline $\mathrm{b}_{4}$ & -0.88 & -0.84 & -0.97 & 1 & \\
\hline & & & & & \\
\hline \multicolumn{6}{|c|}{ Equation 12} \\
\hline & $b_{1}$ & $b_{2}$ & $\mathrm{~K}_{\mathrm{W} 1}$ & $\mathrm{~K}_{\mathrm{W} 2}$ & $\mathrm{~K}_{\alpha}$ \\
\hline$b_{1}$ & 1 & & & & \\
\hline $\mathrm{b}_{2}$ & -0.04 & 1 & & & \\
\hline $\mathrm{K}_{\mathrm{W} 1}$ & 0.03 & -0.06 & 1 & & \\
\hline $\mathrm{K}_{\mathrm{W} 2}$ & 0.13 & -0.07 & 0.32 & 1 & \\
\hline $\mathrm{K}_{\alpha}$ & 0.10 & 0.00 & -0.22 & 0.05 & 1 \\
\hline
\end{tabular}

577

578

579

580

581

582

583 